\title{
Using simulation experiments to test historical explanations: the development of the German dye industry 1857-1913
}

\author{
Thomas Brenner $^{1}$ • Johann Peter Murmann ${ }^{2}$ (D)
}

Published online: 21 November 2015

(C) Springer-Verlag Berlin Heidelberg 2015

\begin{abstract}
In a simulation experiment, building on the abductive simulation approach of Brenner and Werker (2007), we test historical explanations for why German firms came to surpass British and France firms and to dominate the global synthetic dye industry for three decades before World War 1 while the U.S. never achieved large market share despite large home demand. Murmann and Homburg (J Evol Econ 11(2):177-205, 2001) and Murmann (2003) argued that German firms came to dominate the global industry because of (1) the high initial number of chemists in Germany at the start of the industry in $1857,(2)$ the high responsiveness of the German university system and (3) the late (1877) introduction of a patent regime in Germany as well as the more narrow construction of this regime compared to Britain, France and the U.S. We test the validity of these three potential explanations with the help of simulation experiments. The experiments show that the 2nd explanation - the high responsiveness of the German university system - is the most compelling one because unlike the other two it is true for virtually all plausible historical settings.
\end{abstract}

We would like to thank Peter Bearman, Sendil Ethiraj, Shayne Gary, Steve Klepper, Ray Levitt, Dan Levinthal, Richard Nelson, Charles Tilly, participants of a Seminar at the Max Plank Institute for Economics and participants at the Schumpeter conference for helpful comments on earlier, significantly different versions of this paper. We also like to thank two anonymous reviewers for making suggestions that helped us to improve the paper. We would like to thank in particular Ernst Homburg for helping us locate the historical information that was needed to specify important parameters of the simulation experiment that could not be specified from earlier work by Homburg and one of us (Murmann).

Johann Peter Murmann

jee@professor-murmann.net

Thomas Brenner

thomas.brenner@uni-marburg.de

1 Department of Geography, Philipps University Marburg, Deutschhausstr. 10, 35032 Marburg, Germany

2 UNSW Australia Business School, Sydney, NSW 2052, Australia 
Keywords Simulation experiment $\cdot$ Historical development $\cdot$ Dye industry $\cdot$ Industrial development · University education · Patent law

JEL classification $\mathrm{C} 15 \cdot \mathrm{C} 63 \cdot \mathrm{L} 16 \cdot \mathrm{L} 65 \cdot \mathrm{N} 12 \cdot \mathrm{N} 13 \cdot \mathrm{O} 15 \cdot \mathrm{O} 34$

\section{Introduction}

The question of where and how new industries originate and develop is of great interest to policy makers. If one examines the industrial strength of countries and regions today, one usually finds that these strengths can be traced back to a dominating or, at least, strong role in the emergence or early developments of the industry. One example is the chemical industry in Germany. It is strongly connected to the BASF and Hoechst companies, which were founded to sell synthetic dyes and related chemicals, and the firm Bayer, which, after being a trader of natural dyes, ventured into the early synthetic dye industry. There is wide agreement that the synthetic dye industry has been crucial for the development of the German chemical industry (Teltschik 1992). All three firms started not too far from each other along the Rhine river.

Understanding this spatial dimension of the development of industries — why firms producing similar products often cluster in particular regions - has become a very important area of research precisely because it is so important for economic policy making. Two strands can be observed. Some researchers study specific industries and their development in great detail, sometimes including spatial aspects (Klepper 2007; Buenstorf and Klepper 2009; Wenting and Frenken 2011; De Vaan et al. 2013). For other researchers the path-dependence of technology and industry development has become an important research topic in past three decades (David 1985; Arthur 1994; Krugman 1995; Sydow et al. 2009; Heimeriks and Boschma 2014).

While the development of the German chemical industry on the basis of the German synthetic dye industry can be explained on the basis of inter-technological pathdependence, these arguments do not apply to the exceptional developments of the German synthetic dye industry. When the first synthetic dyes were discovered (in France and UK), German firms were imitators and only much later became product innovators in their own right. Furthermore, the important raw materials and by far the largest market for synthetic dyes was in Great Britain, making it somewhat of a puzzle why Germany and not Britain dominated this industry in the period before World War 1. Hence, understanding why Germany came to dominate this industry 15 years after the start of the industry requires a historical perspective (as done in Murmann 2003).

However, historical events are typically caused by a variety of factors. Because events do not recur in the exact same fashion multiple times, there are considerable challenges in developing causal accounts from the one run of history that we can observe. As a consequence, historical examinations are able to propose potential causes, but are not able to test the underlying mechanisms. In this sense, Murmann and Homburg (2001) and Murmann (2003) propose three potentially key explanations for the development of the German dye industry: (1) the high initial number of chemists in Germany at the start of the industry in 1857, (2) the high responsiveness of the German university system and (3) the late (1877) introduction of a patent regime in Germany as well as the more narrow construction of this regime compared to Britain, 
France, and the U.S. However, they are not able to make specific conclusions about the relative importance of these potential causes. Are all causal factors equally important? Could the dominating German market share in 1914 have been caused by a subset of these causal factors? Would the presence of these causal factors under all historically plausible conditions always have produced a dominance of German firms?

The present paper provides much more specific and robust answers to these questions on the basis of a simulation experiment. This is possible because in a simulation approach we are able to utilize at the same time general and case-specific knowledge and analyze counter-factual situations. Although the evolution of the dye industry shows many specific characteristics - some of which we will study in detail here -, it is based on the development of firms, which follows some basic rules that hold for all industries. Firm characteristics and developments have been studied intensively in recent years and many facts that hold for all kinds of industries have been established (an overview is given in Brenner and Duschl 2014). We utilize this information and combine it with the specific knowledge about the development of the synthetic dye industry (provided in Murmann and Homburg 2001; Murmann 2003). This allows us to build realistic simulation models and to test the proposed set of causal reasons for the development with the help of counter-factual simulation experiments.

This is of interest for two reasons. First, we provide much more specific and robust conclusions about the relevance of the different factors for the unusual development of the German dye industry. Although, this development is quite specific (see Section 2), understanding the underlying causes provides information that is also relevant for other industry studies. Second, the combination of general and case-specific information for constructing an adequate simulation model goes beyond the existing approaches. Based on the abductive approach by Brenner and Werker (2007), we are able to produce validated and, hence, reliable results.

The remainder of the paper will proceed as follows. In Section 2 we will provide an overview of the historical development of the synthetic dye industry between 1857 and 1913. Based on the writings of Murmann and Homburg (2001) and Murmann (2003), we highlight three central historical explanations that they offered for why Germany came to dominate the dye industry in the period before 1913. We treat them as the three hypotheses that we test in this paper. Section 3 describes our simulation approach and how the simulation experiments carried out. Section 4 will present the results of the simulation experiments and provide conclusions on the causes of the developments in the German dye industry that are more robust than what a pure historical methodology can offer. Section 5 discusses the contributions of our paper.

\section{The synthetic Dye industry, 1857-1913}

\subsection{A brief history of the industry}

Human societies have dyed textiles for thousands of years, extracting coloring particles from plants and small animals. The first synthetic dye was produced in 1857 by Perkins \& Sons. Wilhelm Henry Perkin - one of the two sons in Perkins's \& Sons - was a student at the Royal College in 1856 when he made a serendipitous discovery. His professor had set the goal for him to synthesize quinine, a drug against malaria. He did 
not succeed with this task but one day he saw a purple coloring substance in his test tube. When textile dyers confirmed that the purple dye was able to dye silk in an appealing purple color, Perkins formed a company with his father and brother and pioneered the synthetic dye industry. The industry received substantial historical attention already in the late 19th century and early 20th century (Caro 1892; Redlich 1914; Thissen 1922). For one, the industry was seen as the first example of a sciencebased industry where a university based research discovery led to the development of a new technology and its commercialization within a very short period of time. Second, contemporaries found it surprising that Germany overtook the early leaders in Great Britain, which was endowed by a much larger home market and the source for raw materials in the first few decades of the industry. By 1913 natural dyes had been almost entirely replaced by synthetic dyes and synthetic dyes had become the largest export item of Germany (Murmann 2003). Furthermore, Germany had dominated the industry for three decades, making British, French, American firms into small players who could not compete effectively with the most successful German and Swiss firms. Thousands of dyes were synthesized in the period until 1914, rendering natural dyes uncompetitive in price and/or quality. After the initial development of aniline dyes in the wake of Perkins invention, the most important natural dyes were replaced by synthetic alizarine in the early 1870 s and synthetic indigo in 1897.

Among scholars of science and technology, the striking case of the German dominance in one of the industries of the 2 nd industrial revolution had been widely known even in the English literature (see for example, Beer 1959; Landes 1969; Freeman 1982). What Homburg and Murmann (2001) added to this literature was that they created a demographic history of the entire global industry - all firms that left any historical trace, even if they were very short-lived, not just focusing on the most successful firms that previous historical writings had focused on. Adapted from Murmann (2013), we summarize some key demographic data on firm entries and exists, demand in individual countries, and country market shares in Table 8 (in the appendix). What the data of Homburg and Murmann showed for the first time is that Germany before 1914 not only produced the largest number of firm start-ups (118) but also the largest number of firm failures (84). Great Britain, by contrast, had only 53 firm entries and only 43 firm failures (for other countries see Table 8). The failure rates in most of the countries were above $80 \%$. The German global market share only amounted to $3 \%$ on 1862 , but by 1873 the German global share had climbed to $50 \%$, by 1893 Germany had $70 \%$ and by $191374 \%$. This is not counting the German owned plants in foreign markets.

\subsection{Central explanations}

Building on the existing historiography and the new data collected on the industry demography with Homburg (Homburg and Murmann 2001), Murmann (2003) offered coevolutionary explanations for how and why German firms came to dominate the industry by 1873 and then cemented their dominance until World War I. In terms of explaining the higher numbers of start-ups compared to Great Britain, Murmann cited two key factors. Dye start-ups required some chemical knowledge and hence the larger number of chemists that existed in Germany before the start of the industry facilitated entry because start-ups could more readily find chemical knowledge. Second, Great 
Britain, France and U.S. issued product patents for synthetic dyes, providing a monopoly to a particular firm for the particular dye. So while patents in the UK inhibited firms from entering industry with the same dye, the absence of an effective patent regime before 1877 allowed German entrepreneurs to enter the industry imitating French and British innovations. The larger number of start-ups in Germany led to fiercer competition in Germany, only allowing the most efficient firms to survive. When British and French firms had their patent expired, they could not manufacture dyes at the same low cost as the strongest German competitors and hence the German firms acquired $50 \%$ world market share by 1873 . By the early 1870 s chemical theory had advanced to a point that it could guide more systematically the search for innovative dyes. When Germany became a unified country in 1871 , the societal groups that wanted Germany also to adopt a patent system gained the upper hand. The representatives of the dye industry together with support from leading chemists, lobbied that in chemical, pharmaceutical and food products only process patents would be granted in order to maintain some competition in the dye industry that industry participants saw as the key reason why German firms outcompeted French and British firms in the previous two decades. After the passage of the all-German patent law in Germany in 1877, the leading German firms started to employ chemists who did nothing else but develop new dyes. This allowed them to develop innovative dyes that achieved higher profits in the market, in turn allowing them to invest more in R\&D and increase their market shares compared to less innovative rivals. Through their trade organization, which was formed in 1877, they lobbied also for German states to increase the number of chemistry graduates who could then be hired to staff expanding corporate R\&D laboratories. Between 1890 and 1914, three of the leading German firms (BASF, Bayer, and Hoechst) producing dyes increased the number of chemists recruited from universities from 350 to 930 (Murmann 2013). Germany universities (in part because federalist structure in Germany and a history of competition among states to possess leading universities) were more responsive to the needs of the dye industry than the British, French, and US universities, making it easier for German firms to staff their growing R\&D laboratories. British firms overcame their own shortage of chemists created by the lower responsiveness of universities to train chemists by importing talent from Germany. But they could not get the same quality of talent at the same price as German firms could, giving Germany an advantage in hiring the best chemists.

\subsection{Historical questions}

To examine parts of the causal claims in the co-evolutionary explanation for German dominance in the synthetic dye industry before World War I, we carry out a simulation experiment of the development of the industry in the five major producer countries: Britain, France, Germany, Switzerland, and the United States. In particular, we want to examine the influence of differences in scientific capabilities in the early years of the industry on the competitive position of national firms over the next five decades. As mentioned earlier, Murmann's (2003) empirical analysis suggests that one of the key reasons why German firms overtook their British and French competitors was that Germany had a larger number of chemists available during the early years of the industry who could become founders of dye firms. 
H1: A larger (smaller) number of German chemists in the first year of the synthetic dye industry (1857) would have caused a larger (smaller) global market share of German firms in this industry in 1913.

When German firms had captured a dominant global market share by 1873 (50\%), collective lobbying campaigns where more successful in Germany than in other countries because the dye industry in Germany due to its size had more political clout. Building on Rosenberg (1998), Murmann (2003) also argued that the German university system was more responsive to the need for additional chemists who could staff the R\&D labs of the large dye firms.

H2: A higher (lower) responsiveness to the demand for chemists in the German university system would have caused a larger (smaller) global market share of German firms in this industry in 1913.

Furthermore, Murmann (2003) argued that the absence of product patents in Germany for the first 20 years and the lobbying efforts of German dye firms to only allow process patents subsequently also had a decisive influence on the market share in 1913.

H3: A larger ability to protect innovations in Germany would have caused a smaller global market share of German firms in this industry in 1913.

\section{Methods}

\subsection{Basic considerations}

We are not the first ones to simulate historical processes. In a path-breaking work Allen (2003) studied the relative importance of key causal factors in determining economic growth in European countries from 1300 until 1800 by running simulations that were calibrated with historical data. While Allen (2003) focused on the key macro variables, we consider the macro and micro level in our approach. Therefore, we follow the abductive simulation approach proposed by Brenner and Werker (2007). To some extent the approach has commonalities with the history-friendly simulation approach developed by Malerba et al. $(1999,2008)$ but it is also different in important ways. The abductive simulation approach has three specific characteristics: First, two levels are explicitly distinguished: the level of the underlying mechanisms and the level of implications. Second, the simulation model should be kept as general as necessary, instead of aiming at developing exactly one simulation model. Third, available knowledge on both levels should be used as much as possible to narrow the set of potential simulation models.

In our case the level of underlying mechanisms contains the developments of the individual firms, the markets for dyes, the education and employment of chemists, the ability to obtain individual patents, as well as all processes and mechanisms important for these developments and their interaction. The level of implications is the global development of the synthetic dye industry, especially the distribution of market shares between the countries and the number of active firms. 
We proceed in four steps: First, we develop a very general model (see Section 3.2). Then, historical knowledge on the implication level — such as the number of start-ups, the number of firms active and the distribution of market shares among the countries - is used to identify realistic parameter sets (see Section 3.3). In a third step, we conduct counter-factual simulation experiments in order to test our hypotheses (see Section 3.4). The results of the counter-factual simulations are studied statistically (see Section 3.5).

\subsection{Simulation model}

The basic element of our simulation model is the development of each single firm. Brenner and Duschl (2014) proposed a general model of firm and market dynamics that is in line with all well-established stylized facts and offers the possibility to further specify and adapt the model to specific industries. Hence, this model provides an excellent starting point for modelling the development of the dye industry.

The model by Brenner and Duschl (2014) is based on the assumption that the considered market (in our case the market for synthetic dyes) consists of numerous separate submarkets (called market packages) and that firms compete in a monopolistic competition for these market packages, so that at each point in time each market package is satisfied by exactly one firm. Market packages appear and disappear and change in size randomly. There is a competition between firms (including a potential start-up) for existing and appearing market packages with the competition strengths crucially depending on the innovativeness of firms. Firms are characterized by the innovation strategy (ranging from an imitative to an innovative focus), their age and their competitive strength, which follows a random walk (see Brenner and Duschl 2014 for further details). Brenner and Duschl (2014) carefully tested whether their model is in line with the stylized knowledge about firm growth and firm characteristics. Therefore, we use this model but adapt a number of details to the historical situation in the synthetic dye industry, such as running a real time period from 1957 to 1913 (simulating each day as proposed by Brenner and Duschl (2014)) and using six independent regions: United Kingdom (UK), Germany (G), France (F), Switzerland (SW), United States (USA), and the rest of the world $(R E S T)$. The first five regions represent the major dye producing countries before 1914, whose development and global market share is under investigation. We created the umbrella category "rest of the world" to represent the demand in all other countries. Each actor (firm, chemist, and patent) is assigned to one of the first five regions.

Furthermore, a number of aspects are of crucial relevance for testing our hypotheses. Therefore, we go into more details in the modelling of these aspects. In this sense, we make some smaller expansions of the model by Brenner and Duschl (2014) by allowing firms to change their strategies (see appendix A 2.1), allowing firms to generate innovations dependent on firm characteristics such as the number of chemists employed (see appendix A 2.2), and making the number of start-ups dependent on the availability of chemists in the countries (see appendix A 2.2). Larger modification are done in the definition of the market space and with respect to the two central aspects of our 
analysis: chemists and patents (both being not present in the model by Brenner and Duschl). These modifications are described in detail here.

\subsubsection{Market space}

Historically dyes mainly compete with respect to two factors: Their type and their price-quality ratio. Therefore, we use a value, $y_{m}$, which defines the type of the product, and a value, $a_{m}$, which characterizes the technological advancement in price-quality ratio. The total market space is spanned by these two variables. We start the simulation always with two firms (one in UK and one in France) existing, supplying two market packages of a randomly drawn type and with a technological advancement of 0 . All other market packages are not supplied by synthetic dye firms at the beginning (they are supplied by traditional dye firms). At the beginning of a simulation run these market packages are created with random values of $y_{m}$ ranging between 0 and 1 and $a_{m}$ ranging between 0 and $a_{\text {init,natural }}$. $a_{\text {init,natural }}$ reflects how much more attractive (price-quality ratio) the best natural dye is compared to the first synthetic dye. $a_{\text {init,natural }}$ is chosen randomly from a range between 20 and 100 for each simulation group. With time the synthetic dyes become more advanced due to innovations (see appendix A 2.2) so that their values go beyond $a_{\text {init,natural }}$ and they finally replace (almost) all natural dyes on the market. The number of initial market packages is chosen such that it reflect the market for natural dyes in 1957, so that these market packages reflect the potential market that could have been overtaken by synthetic dyes. The strength of competition between market packages and the range of innovations within the market space are deduced from historical knowledge about the market (see appendix A 2.3)

While the total market size develops randomly in the model by Brenner and Duschl (2014), the real market development is well known, at least in parts, in our case. We use the available historical information to determine at each point in time the total market size (see appendix A 2.4). While we keep the occurrence of new market packages random (as in the original model), we make the total market size to fit the historical record by removing each day the required number market packages, instead of making their disappearance a random event as in the original model. The most unattractive market packages are removed first (see appendix A 2.4 for details).

\subsubsection{Chemists}

According to the historical records on the synthetic dye industry, chemists play an important role in the development of this industry. Therefore, in contrast to the original model, chemists and their employment are explicitly modeled and each firm is assumed to employ at least one chemist. Furthermore, the number of chemists increases with the size of the firm and depends on the firm's innovation strategy (for details see appendix A 2.5).

We assume that chemists first have to be trained in universities. Training is assumed to take 3 years. Hence, the number of chemistry students deciding to start university education at a particular time influences the number of available chemists 3 years later. Education is relevant within countries mainly because migration was historically a rare event, which we nevertheless consider in the simulation model according to the real data (see appendix A 2.5). 
The initial numbers of chemists in each country, denoted by $c_{\text {init,reg, }}$, are set in accordance with the estimates given in Table 10 (in the appendix). We assume that the study of chemistry can be started once a year and calculate every year the number of new students. This number depends on the national system of education and the conditions in the labor market. The actual demand for chemists is assumed to be represented well by the current number of employed chemists $c_{\text {emp,reg }}(t)$ in a country reg ("reg" standing for our five explicitly modeled countries UK, Germany $(G)$, France (F), Switzerland $(S)$ and the US). In 3 years time, when the now starting students enter the labor market the demand may have changed. We assume that national governments treat this issue differently. The largest increase in the number of chemists observed in the history of the dye industry before World War I is the jump from 380 to 900 chemists in Germany during the period from 1851 to 1865 . On average, this implies that the number of chemists increased by $6.5 \%$ each year or by approximately $20 \%$ within 3 years. Education clearly responds to an increase of demand. The expected increase in the number of chemists is assumed here to be based on two factors: a basic preparation for increases, $e_{r e g}-$ which we call the responsiveness of the national university system - and additional education that is caused by lobbying. Lobbying is the more effective the higher the market share of the local firms is. For this reason each year the number of new chemistry students is chosen such that the number of chemists 3 year later is given by

$$
c_{\text {available,reg }}(t+3 y e a r s)=c_{\text {empl }, \text { reg }}(t) *\left(e_{\text {reg }}+\lambda_{\text {reg }} \cdot m_{\text {reg }}(t)\right)
$$

where $m_{\text {reg }}$ denotes the joint market share of all firms in country reg. $\lambda_{\text {reg }}$ represents the influence of lobbying on the national education system. Our empirical analysis implies that $\lambda_{\text {reg }}$ should not be greater than 0.2 , because otherwise the lobbying might cause the number of chemists to increase by more than $20 \%$ (within 3 years) and an increase by $20 \%$ is the maximum that we observe in history. Therefore, its range is set to $0<\lambda_{\text {reg }}<0.2$. Given the historical information, we set $1<e_{\text {reg }}<1.2$.

\subsubsection{Patents}

Selling products is restricted by patent laws. Each time a firm discovers a new product (market package) the simulation program checks whether a patent exists for this product in the country in which the product should be sold. If such a patent exists and is held by another firm, the firm does not create and own this market package. If no such patent exists and has never existed (patents that have expired cannot be granted again) but the home country offers patent protection, the firm patents the product.

Different patent laws existed in the countries modeled. First, patent laws did not exist in all countries during the entire time span from 1857 to 1913. Second, patent laws differed between the countries. All countries in our simulation except Germany granted patents for product innovations. After 1877, Germany granted process patents. We model this by defining ranges within the product space that patents cover. This means that each patent has a range with respect to the technological type, $y_{m}$, and the technological advancement, $a$, of products. 
Patent counts show that there were between 1000 and 4000 different types of dyes patented in the different countries. If we take this as an approximation of the number of different types of products in our simulation of patents, each patent covers a range of between 0.00025 and 0.001 in the type dimension. In addition, in Germany process innovations were patented. These cover only one innovation step, so that their range is assumed to be 1 in the dimension of the level of technological advancement.

Because successful litigation often cut short the life-span of a patent, all patents are assumed to hold for between 5 and 20 years (in accordance to the historical record). All characteristics of patents are summarized in Table 1.

In addition, in Great Britain numerous patent applications failed in the years 18561862. Therefore, the probability of obtaining a patent during that time in Great Britain is reduced to $50 \%$. Once patents expire, it is assumed in the simulation that the same product cannot be patented again. The respective products can then be produced and sold by all firms forever.

\subsection{Calibration of simulation model}

The model by Brenner and Duschl (2014), even in its restricted form, is designed to be flexible enough to capture all different kinds of industries. While we use the specific parameter settings in the Brenner and Duschl (2014) model that are able to generate all stylized facts about firm growth and market dynamics, we keep the additional parameters of our extension very general. Only those features, for which exact numbers are available from historical records, such as the initial number of chemists, the demand for dyes, the patent laws and so on are fixed in the simulation model.

Therefore, it is necessary to calibrate the model and find the parameter specifications that are in line with the real development of the synthetic dye industry. In line with the proposal of Brenner and Werker (2007) we do not aim to identify one specific parameter set that represents reality. The available knowledge on the real developments of the synthetic dye industry does not allow us to determine exactly one simulation model that represents reality for sure. For this reason, we have to identify a whole range of possibly realistic simulation models (parameter sets) and check for each of them whether our hypotheses are confirmed.

Historical records provide quite some information that can be used for checking whether each parameter set leads to realistic developments. We use information about

Table 1 National patent characteristics

\begin{tabular}{llllll}
\hline & Existence & $\begin{array}{l}\text { Range in type } \\
\text { dimension }\end{array}$ & $\begin{array}{l}\text { Range in technological } \\
\text { dimension }\end{array}$ & $\begin{array}{l}\text { Minimum } \\
\text { duration }\end{array}$ & $\begin{array}{l}\text { Maximum } \\
\text { duration }\end{array}$ \\
\hline UK & $1856-1913$ & $0.001-0.0025$ & $10-50$ & $5-10$ years & $15-20$ years \\
G & $1877-1913$ & $0.001-0.0025$ & 1 & 5 5-10 years & $15-20$ years \\
F & $1856-1913$ & $0.001-0.0025$ & $10-50$ & $5-10$ years & $15-20$ years \\
SW & $1908-1913$ & $0.001-0.0025$ & $10-50$ & $5-10$ years & $15-20$ years \\
USA & $1856-1913$ & $0.001-0.0025$ & $10-50$ & $5-10$ years & $15-20$ years \\
\hline
\end{tabular}


macro patterns: In total there had been 289 start-ups in the dye industry in the five major producers countries between 1856 and 1913 (see Appendix 1). In Germany 118 start-ups are counted (Murmann 2013). We accept all simulation runs that lead to between half and twice these numbers (i.e., between 59 and 236 German start-up and between 144 and 578 start-ups in total). Furthermore, we know that the world market share by German firms had been approximately $75 \%$ in 1913 , so that we accept only simulation runs that end in a German market share between 65 and $85 \%$.

The time structure of the industry development is also an important aspect. Therefore, it is important that the simulation model also represents the time course adequately. We use the year 1871 as a point of time for checking whether the early developments are represented adequately. Historical records show that the world production of synthetic dye was $3500 \mathrm{t}$ in 1871 (Murmann 2003 , pp. 38). Simulation runs are accepted only if the total production in 1871 is between half and twice that value (between 1750 and $7000 \mathrm{t}$ ). The number of start-ups before 1871 was historically 25 in the UK, 38 in Germany, 36 in France, 15 in Switzerland and 3 in the US (Homburg and Murmann 2014). For this reason, we set the boundaries for accepting simulation runs again to half and twice the historical values: $12-50$ for UK, 19-76 for Germany, 18-72 for France, 7-30 for Switzerland and 1-6 for the US.

\subsection{Simulation experiment}

Given the simulation model and the validation criteria, the simulation experiment is conducted as follows. The simulation model contains many parameters for which quite large ranges are defined. We classify these parameters either into one group called "nuisance parameters" that contains all parameters that are not of core interest in our analysis or into a second group called "central parameters" that contains the parameters whose impacts we seek to study in detail. Central parameters are those parameters that are connected to our hypotheses, namely the number of initial chemists in Germany, the reactiveness of the German university system and the specific patent law in Germany.

For the simulation experiment we repeated the following procedure (see Fig. 1 in the appendix) more than 7 million times. We draw a random set of parameters from their defined ranges, run the simulation and check whether this parameter set is able to reproduce history, meaning that it produces a simulation run that satisfies the calibration criteria defined above. If this is the case, we start the simulation experiment. This means that now the central parameters are varied systematically. For the initial number of chemists in Germany (the real value is 54) we use three different values: $c_{i n i t, G}=25,54,85$. For the responsiveness of the German university we also use three values: $e_{G}=1,1.1,1.2$. For the patent laws we use two settings: One setting reflects the actual historical situation, while the other setting assigns Germany the same patent laws that existed in France. We run 100 simulations for each of these values of the central parameters in combination with the setting of the nuisance parameters that passed the calibration test. Each simulation run starts in 1857 and ends in 1913. We record for each simulation run the market share of German firms in 1913 since this is the key outcome variable that we want to study. 
In total we conducted the simulation experiment for 4000 parameter sets. All simulation runs for one setting of the nuisance parameters is called a group of simulations.

Note that the method we use here represents a Monte-Carlo approach since we run simulations across the entire range of empirically possible parameter settings.

\subsection{Statistical methods}

Each group of simulations reflects one model specification and, therefore, one potential representation of the real world. If a large number of such groups are randomly drawn from the parameter ranges, it is likely that some simulation groups contain nuisance parameter values that are very similar to the true historical values. If, furthermore, the overall structure of the model is adequately chosen, these simulation groups will approximate well the true description of reality.

The number of simulation runs has to be numerous enough so that within a group of simulations a sufficient number of data points are generated to make statistical analyses feasible. Remember that within a group of simulations all nuisance parameters are the same for all simulation runs. In a first step, we analyze each group of simulations separately, so that in this first analysis the nuisance parameter do not play a role. In order to obtain a detailed picture of the impact of our central variable we compare the results for seven pairs of settings. Namely, we compare the market share held by German firms in 1913 between the simulation runs with $c_{\text {init, } G}=85$ and $c_{\text {init, } G}=54$, between the simulation runs with $c_{\text {init, } G}=85$ and $c_{\text {init, } G}=25$, between the simulation runs with $c_{\text {init }, G}=54$ and $c_{\text {init }, G}=25$, between the simulation runs with $e_{G}=1.2$ and $e_{G}=$ 1.1 , between the simulation runs with $e_{G}=1.2$ and $e_{G}=1$, between the simulation runs with $e_{G}=1.1$ and $e_{G}=1$, and between the simulation runs with the actual historical German patent laws and with counterfactual German patent laws that we set identical to those in France. The U-Test of Mann and Whitney is an adequate statistical tool for these (using a significance level of $5 \%$ ). The comparison is done for each simulation group separately, making it possible to determine for each simulation group seven results. Each result can be reflected by " + " if the average market share of German firms $<m_{G}>$ is significantly higher for the first setting than for the second setting, by "-_" if it is significantly smaller for the first setting, and by " 0 " if no significant difference is detected (see Table 2 for an example). Such a table is obtained for each simulation group.

Table 2 Comparison of the average value of the market share $<\mathrm{m}_{\mathrm{G}}>$ of German firms dependent on the setting of the central parameters ("+" represents cases in which the first setting causes a significantly higher value of $<\mathrm{m}_{\mathrm{G}}>$ than the second setting, significance level: 0.05 ; "-" represents cases with the opposite finding; " 0 " represents cases with no significant difference)

\begin{tabular}{llllllll}
\hline & $\begin{array}{l}c_{\text {init }, G}=85 \\
\text { vs. } c_{\text {init }, G}=54\end{array}$ & $\begin{array}{l}c_{\text {init }, G}=85 \\
\text { vs. } c_{\text {init }, G}=25\end{array}$ & $\begin{array}{l}c_{\text {init }, G}=54 \\
\text { vs. } c_{\text {init }, G}=25\end{array}$ & $\begin{array}{l}e_{G}=1.2 \\
\text { vs. } e_{G}=1.1\end{array}$ & $\begin{array}{l}e_{G}=1.2 \\
\text { vs. } e_{G}=1\end{array}$ & $\begin{array}{l}e_{G}=1.1 \\
\text { vs. } e_{G}=1\end{array}$ & $\begin{array}{l}\text { Real patent } \\
\text { law vs. French } \\
\text { patent law }\end{array}$ \\
\hline $\begin{array}{l}\text { Comparison } \\
\text { result }\end{array}$ & + & + & 0 & 0 & + & 0 & + \\
\hline
\end{tabular}


Above we argued that a result only holds in general if it holds for each simulation group. One way, then, of analyzing the results across all simulation groups is to count up the number of simulation groups for which a positive difference is obtained in a certain comparison. Since we carry out 4000 simulation groups in total, we could present 4000 tables in the form of Table 2. It is more expedient, however, to present simply the share of "+"s in the analysis below, as will be done in Tables 3,5 and 6. This means that each cell will represent the probability for a significant difference.

The set of results that we obtain for the different simulation groups represent all possible types of causal relations that might exist in the real world. Hence, the fact that we are only able to restrict the (nuisance) parameters to certain ranges leads to the fact that we obtain also ranges of outcomes. To claim otherwise would be an exaggeration of what simulations can accomplish. If, however, the same causal relation is found for all groups of simulations and if the model is an adequate representation of reality, a very strong inference can be made that the causal process does indeed operate in the real world in the manner specified.

If non-uniform causal relations emerge, our approach provides the option to study how the various nuisance parameters influence the relationship between the central variables and the simulated outcome. For each group of simulation (meaning for each setting of the nuisance parameters) and each pair of settings of the central variables (e.g., $c_{\text {init }, G}=85$ vs. $c_{\text {init }, G}=54$ ) we obtain a statistical statement about whether one setting leads to a significant higher market share of German firms in 1913 than the other. We define this finding as the dependent variable with two possible values (significant higher share $(=1)$ or not $(=0)$ ) and regress this variable with all nuisance parameters as independent variables, e.g.,:

$$
P_{g}\left(m_{G}\left(c_{\text {init }, G}=85\right)>m_{G}\left(c_{\text {init }, G}=54\right)\right)=f\left(B \cdot X_{g}\right),
$$

where $P()$ stands for the probability of the statement in the bracket to be true, $f$ represent a logistic function, $B$ stands for the regression parameters, $X$ represents all nuisance parameters of the model and the index $g$ signifies the simulation groups. This regression approach allows us to identify for each comparison of central parameter settings the nuisance parameters that influence the result of the comparison.

Table 3 Percentage of simulation groups (settings of the nuisance parameters) for which the market share $<\mathrm{m}_{\mathrm{G}}>$ of German firms increases significantly if the initial number of German chemists is increased

\begin{tabular}{llll}
\hline & $\begin{array}{c}c_{\text {init }, G}=25 \rightarrow \\
c_{\text {init } G}=54\end{array}$ & $\begin{array}{l}c_{\text {init }, G}=25 \rightarrow \\
c_{\text {init, } G}=85\end{array}$ & $\begin{array}{l}c_{\text {init },}=54 \rightarrow \\
c_{\text {init }, G}=85\end{array}$ \\
\hline Significance level : 0.05 & $48.6 \%$ & $77.6 \%$ & $25.4 \%$ \\
Significance level : 0.01 & $30.4 \%$ & $63.2 \%$ & $11.3 \%$ \\
Significance level : 0.001 & $15.2 \%$ & $44.2 \%$ & $2.8 \%$ \\
\hline
\end{tabular}




\section{Results}

From the historical records we proposed above three different hypotheses about the causes for the high market share of German firms in 1913. The simulation experiment allows us to test whether the development would have been different if these three causes would not have been present. To this end, we examine the effects of each potential cause separately in the following.

\subsection{Chemists (Hypothesis 1)}

Let us start with the high number of chemists in Germany in 1857. While in the UK and France there have been around 21 and 34 chemists in 1857, the number was approximately 54 in Germany. Therefore, we test with our simulation experiment whether the developments would have been different if there would have been 25 (similar to UK and France) or 85 chemists in Germany in 1857. The results are given in Table 3 .

Table 3 shows that we do not obtain a clear result for the impact of the initial number of German chemists on the development of the German firms' market share. If this initial number would have been comparable to the numbers in UK and France $\left(c_{i n i t, G}=25\right)$, the final market share of German firms would have been in nearly $50 \%$ of the cases significantly (significance level: 0.05) lower. However, this result is far from being general and it becomes less frequent if the significance level is decreased. Furthermore, it strongly depends on the setting of the nuisance parameters. All settings that are studied in our simulation experiments are potentially realistic, so that we are not able to conclude whether one of those settings leading to a significant influence of the initial number of German chemists or one of those settings leading to no significant change is most realistic. Hence, a final conclusion cannot be drawn.

However, we can study the nuisance parameters that influence whether initial German chemists have a significant impact on the development. To this end, we conduct a logistic regression with the question whether the initial German chemists have a significant influence as dependent and all nuisance parameters as independent variables (see Section 3.5). The results for all significant nuisance parameters are listed in Table 4.

It is no surprise that the relevance of the initial number of chemists for the dominance of the German synthetic dye industry in 1913 depends most crucially on $\Phi_{\text {start-up,chem }}$, denoting the dependence of the number of start-ups in a country on the number of unemployed chemists there. Further aspects that play a role are the stability of submarket (market package) sizes $\left(\sigma_{d}\right)$, the ability of firms to adapt their production to demand changes $\left(\mu_{\text {T,adapt }}\right)$, the responsiveness of the German, French and UK university system $\left(e_{G}, e_{F}\right.$ and $\left.e_{U K}\right)$, the influence of lobbying on the German university system $\left(\lambda_{G}\right)$ and the duration of effect of innovation success on further innovations. Strongly changing market package sizes would mean that the whole synthetic dye demand fluctuated strongly in the required characteristics of the products, implying a lower relevance of the initial conditions (such as the initial number of chemists). Similarly, if innovation success leads to further long-lasting innovation capability, the initial conditions have a 
Table 4 Nuisance parameters that significantly influence the relevance of the initial number of German chemists

\begin{tabular}{llc}
\hline Nuisance parameters & Estimate & $p$-value \\
\hline Dependence of start-ups on chemists $\left(\Phi_{\text {start-up,chem }}\right)$ & $5.09^{* * * *}$ & 0.000 \\
Stability of submarket sizes $\left(\sigma_{d}\right)$ & $-75.2^{* * * *}$ & 0.000 \\
Adaptiveness of firms to demand changes $\left(\mu_{T, a d a p t}\right)$ & $-2.86^{* * *}$ & 0.000 \\
Responsiveness of the German university system $\left(e_{G}\right)$ & $4.88^{* * *}$ & 0.000 \\
Responsiveness of the French university system $\left(e_{F}\right)$ & $-2.63^{* * *}$ & 0.000 \\
Responsiveness of the UK university system $\left(e_{U K}\right)$ & $-1.83^{* *}$ & 0.005 \\
Influence of lobbying in Germany $\left(\lambda_{G}\right)$ & $3.38^{* * *}$ & 0.000 \\
Duration of effects of past innovation success on further innovation performance & $1.87^{* * *}$ & 0.000 \\
Strength of market competition & $-50.9^{* *}$ & 0.001 \\
Transportation costs between countries & $-1.59^{*}$ & 0.012 \\
Number of observations & 4000 & \\
AIC & 4438.5 & \\
Cox \& Snell pseudo $\mathrm{R}^{2}$ & 0.175 & \\
Hosmer \& Lemeshow's goodness-of-fit test & 0.09814 & \\
\hline
\end{tabular}

more permanent impact. It is less clear why the parameter $\mu_{\text {T,adapt }}$ has an influence. Maybe better adapting incumbents leave less room for start-ups and make the number of initial chemists less relevant. Finally, the impact of the initial number of chemists is stronger if the system keeps the number high due to lobbying and a strong response of the university system to the demand for chemists. A low responsiveness of the university system in the other important countries, France and UK, also helps.

To sum up, we find that the initial number of chemists plays an important role only under some specific historical conditions. Because we do not know whether all conditions were historically present, we are not able to draw a final conclusion about the contribution of the initial number of chemists to German firms becoming the dominant players in the synthetic dye industry (Hypothesis 1).

\subsection{University responsiveness (Hypothesis 2)}

Our simulation model contains a parameter $e_{\text {reg }}$ ("reg" standing for our five countries) that determines the number of chemists that are educated in relation to the number of chemists currently employed. We called this the responsiveness of the university system to the needs of firms. This parameter cannot be estimated from historical records, but historical records make values between 1 and 1.2 realistic and the historical literature makes it clear that the German university system is characterized by higher values than present in the other countries. This is confirmed by our simulation validation. Although the value of $e_{G}$ is randomly drawn from the range $[1,1.2]$, the average value is 1.14 for those settings that are validated as potentially realistic. 
Furthermore, in approximately $80 \%$ of the setting that are validated as potentially realistic the value for Germany is higher than those for the other countries. Hence, the value of $e_{G}$ has to be quite high for the simulation model to be able to explain the high market share of German firms in 1913. Table 5, presenting the share of simulation groups with a significant impact of $e_{G}$ on the final German market share, confirms this.

The results in Table 5 provide a quite clear picture. In most simulation groups an increase in the responsiveness $e_{G}$ of the German university system leads to a significantly higher market share of German firms in 1913. If we consider an increase from $e_{G}=1$ to $e_{G}=1.2$ this result is obtained in almost all simulation groups, even if we lower the significance level. Thus, although a very small probability for error remains, we can conclude that our simulation experiment confirms Hypothesis 2: In the development of the synthetic dye industry the high responsiveness of the German university system has played a strong role, contributing significantly to the development of the dominant German market position.

\subsection{Patent law (Hypothesis 3)}

The German patent laws have been quite different from the patent laws in the other important countries in 1857 and this has been highlighted by Murmann (2003) as one of the reasons that Germany built up capabilities that allowed it to dominate the industry for decades. To examine this historical interpretation, it is useful to study whether the developments of the German synthetic dye industry would have been the same if the patent laws in Germany had been similar to those in the other countries. For this reason, we experiment in our simulations with patent laws in German similar to those in France. The results of this experiment are listed in Table 6.

Similar to the initial number of German chemists, the simulation experiment leads to mixed results on the question whether the specific patent law situation in Germany was important for the development of the German synthetic dye industry.

Again, we can study the nuisance parameters that influence whether the German patent law has a significant impact on the development. As in the case of the initial number of German chemists, we conduct a logistic regression with the question of whether the German patent law has a significant influence as dependent and all

Table 5 Percentage of simulation groups (settings of the nuisance parameters) for which the market share $<\mathrm{m}_{\mathrm{G}}>$ of German firms increases significantly if the responsiveness $\mathrm{e}_{\mathrm{G}}$ of the German university system is increased

\begin{tabular}{llll}
\hline & $\begin{array}{l}e_{G}=1 \rightarrow \\
e_{G}=1.1\end{array}$ & $\begin{array}{l}e_{G}=1.1 \rightarrow \\
e_{G}=1.2\end{array}$ & $\begin{array}{l}e_{G}=1 \rightarrow \\
e_{G}=1.2\end{array}$ \\
\hline Significance level : 0.05 & $92.1 \%$ & $93.1 \%$ & $98.1 \%$ \\
Significance level : 0.01 & $88.3 \%$ & $89.9 \%$ & $96.8 \%$ \\
Significance level : 0.001 & $83.1 \%$ & $84.8 \%$ & $94.9 \%$ \\
\hline
\end{tabular}


Table 6 Percentage of simulation groups (settings of the nuisance parameters) for which the market share $<\mathrm{m}_{\mathrm{G}}>$ of German firms is significantly higher if the German patent laws are modeled as they have been in reality instead of as they have been in France

German patent laws as in France $\rightarrow$ Real German patent laws

Significance level : 0.05

$49.1 \%$

Significance level : 0.01

$31.8 \%$

Significance level : 0.001

$17.9 \%$

nuisance parameters as independent variables. The results for all significant nuisance parameters are listed in Table 7.

The results show that the relevance of patent laws depends crucially on a large number of characteristics. Six of these characteristics relate to market packages and their development. We find that the specific patent law in Germany contributes more to the dominance of German firms in the synthetic dye industry if market packages (1) are small $\left(\mu_{d, \max }\right)$, (2) their size is very stable $\left(\sigma_{d}\right)$, (3) they are replaced rarely due to innovations $\left(\Phi_{\text {inno, },}\right),(4)$ competition is strong, $(5)$ larger firm have no advantage in

Table 7 Nuisance parameters that significantly influence the relevance of the German patent law

\begin{tabular}{|c|c|c|}
\hline Nuisance parameters & Estimate & p-value \\
\hline Stability of submarket sizes $\left(\sigma_{d}\right)$ & $-99.2 * * *$ & 0.000 \\
\hline Maximal size of submarkets $\left(\mu_{d, \max }\right)$ & $-.0054 * * *$ & 0.000 \\
\hline Responsiveness of the German university system $\left(e_{G}\right)$ & $7.07 *$ & 0.000 \\
\hline Responsiveness of the French university system $\left(e_{F}\right)$ & $-3.16^{* * *}$ & 0.000 \\
\hline Responsiveness of the UK university system $\left(e_{U K}\right)$ & $-2.49 * * *$ & 0.000 \\
\hline Basic innovation rate $\left(\Phi_{\text {inno,o }, 0}\right)$ & $-2.57 * * *$ & 0.000 \\
\hline Adaptiveness of firms to demand changes $\left(\mu_{T, a d a p t}\right)$ & $-2.04 * * *$ & 0.000 \\
\hline Dependence of start-ups on chemists $\left(\Phi_{\text {start-up,chem }}\right)$ & $1.86^{* * *}$ & 0.000 \\
\hline Strength of market competition & $109.7 * * *$ & 0.000 \\
\hline Advantage of larger firms in competition & $-22.7 * * *$ & 0.000 \\
\hline Influence of lobbying in Germany $\left(\lambda_{G}\right)$ & $3.28 * * *$ & 0.000 \\
\hline Initial technological advancement of natural dyes $\left(a_{\text {init,natural }}\right)$ & $-0.0067 * * *$ & 0.000 \\
\hline Range of innovation $\left(\Phi_{\text {type,inno }}\right)$ & $107.7 * * *$ & 0.000 \\
\hline Frequency of imitating entrants $\left(\mu_{T, n e w}\right)$ & $0.029 *$ & 0.040 \\
\hline Number of observations & 4000 & \\
\hline AIC & 4434.8 & \\
\hline Cox \& Snell pseudo $\mathrm{R}^{2}$ & 0.178 & \\
\hline Hosmer \& Lemeshow's goodness-of-fit test & $0.00473 * * a$ & \\
\hline
\end{tabular}

\footnotetext{
${ }^{\text {a }}$ A detailed look at the deviations from the logistic distribution does not provide evidence for any alternative distribution. The deviations seem to be rather random in their structure and the high number of observation seems to contribute to the detection of these deviations. Quadratic or interaction terms do not change the outcome of the goodness-of-fit test and do not lead to additional significant estimates
} 
competition, and (6) imitative entries are frequent $\left(\mu_{T, \text { new }}\right)$. Remember that our model is based on monopolistic competition and that smaller and, thus, more market packages mean that the demand is more segmented offering more possibilities for entries and niche producers. Our results imply that patent laws have played an important role if demand was strongly segmented with strong competition and difficult conditions for large incumbents, while the market packages were characterized by a high stability and rare replacement by innovative new submarkets.

In addition, we find two nuisance parameters $\left(\mu_{T \text {,adapt }}\right.$ and $\left.a_{\text {init,natural }}\right)$ to be relevant that make the initial development less dynamic (see Section 4.1). This seemingly implies that the non-existence of patent laws in Germany at the beginning is more important for the development of the German dye industry than the different structure of the later introduced German patent law. To examine this further, we conducted additional simulations. These simulations show that introducing a product patent law in Germany in 1877 instead of a process patent law would also have led to a similarly high German market share in 1913. However, introducing the Germany kind of process patent law already before 1856 would have led to an even higher German market share in 1913. Hence, the German timing and the German kind of patent law are both individually beneficial in at least $50 \%$ of the simulation settings. Interestingly, introducing the specific German process patent law earlier would have even been more beneficial than introducing it in 1877 (this is found in $63 \%$ of the realistic simulation settings).

Furthermore, we find an interaction between our potential explanations. If chemists are more relevant for the start-up activities $\left(\Phi_{\text {start-up,chem }}\right)$, the responsiveness of the German university system is high $\left(e_{G}\right)$ (especially in comparison to France and UK), and lobbying is influential in Germany $\left(\lambda_{G}\right)$, patent laws in Germany have a higher influence, probably because there is more innovation activity in the synthetic dye industry in Germany. Hence, it is quite likely that although our results suggest that the responsiveness of the Germany university system was most crucial, the specific patent law development additionally increased the German market share even further.

\section{Conclusions}

In this paper, we use simulation experiments to examine whether specific circumstances are decisive for the observed historical developments. While historical analyses are able to provide detailed information about the development of industries, they are not able to examine with precision whether history would have been different if certain circumstances would have been different. Simulation experiments allow for such counter-factual analyses with multiple factors playing a role. The reliability of the results of such simulation experiments, however, crucially depend on the reliability of the basic simulation model. For this reason, we apply the abductive simulation approach of Brenner and Werker (2007), using as basic model the well-validated firm growth model by Brenner and Duschl (2014), and we further validate our simulation models with historical data. All models identified as potentially realistic are analyzed, providing stochastic statements about the relevance of the potential causes that are identified in the historical analyses. 
We study the historical development of the synthetic dye industry between 1857 and 1913. The interesting development in this industry is that German firms managed to obtain a global market share of approximately $75 \%$ in 1913 even though British and French firms initially dominated the industry. Historical studies (Murmann and Homburg 2001 and Murmann 2003) provide three potential explanations for this change in industrial leadership: (1) the high initial number of chemists in Germany at the start of the industry in 1857, (2) the high responsiveness of the German university system and (3) the late (1877) introduction of a patent regime in Germany as well as the more narrow construction of this regime compared to Britain, France and the U.S. With the help of counter-factual simulation experiments we test all three potential explanations.

Our main finding is that the high responsiveness of the German university system has almost surely contributed to the development of a dominant German position in the synthetic dye industry. The synthetic dye industry seems to be an industry in which the university system was crucial for its development. Interestingly, even though the inventor of the first synthetic dye was a student at the Royal College of Chemistry in London, many of the early dyes both in the UK and France were not developed in university laboratories. University professor as inventors of new dyes became more important later when they had learned how economically valuable these dyes would be. Still later, from the 1880 s, the R\&D laboratories of the big dye firms became the most important source of new dyes. These large R\&D laboratories did not train chemists themselves but relied on universities for the training of their chemists. The education of chemists by universities has, according to our analysis, been the crucial factor giving a national industry a competitive advantage. Hence, our results contribute also to the discussion about the relevance of university education for the local economic development. On the national level our study shows rigorously that university education was crucial for the development of the synthetic dye industry. Whether this is also true in other industries has to be examined in further studies.

For the influence of the initial number of chemists and the patent laws we do not obtain conclusive results. The final answer depends on the question of which simulation setting is the realistic one. According to the arguments by Brenner and Werker (2007) it is not possible to identify one correct model. As a consequence, it may not be possible to draw a final conclusion from simulation experiments unless they show uniform results. We could not show uniform results for the influence of the initial number of chemists across all historically plausible conditions. However, from our analyses, we conclude that the number of chemists in Germany play a role if the number of start-ups depends crucially on the number of unemployed chemists. Furthermore, patent law are relevant if demand is strongly segmented and stable in its structure. Finally we find that the specific patent law made at least an additional contribution to the development of the Germany synthetic dye industry.

Additional studies of this kind on other industries will make it possible to assess whether our findings apply to all industries or only are specific to particular sectors in the economy. 


\section{Appendix 1: some data on the synthetic Dye industry}

Table 8 Indicators for the Evolution of National Synthetic Dye Industries and the Rest of the World, 1857-1914

\begin{tabular}{lllllll}
\hline & Great Britain & Germany & France & Switzerland & U.S. & Rest of World \\
\hline $\begin{array}{l}\text { 1. Total firm } \\
\text { entries }\end{array}$ & 53 & 118 & 68 & 32 & 28 & \\
$\begin{array}{l}\text { 2. Entries until } \\
1870\end{array}$ & 25 & 38 & 36 & 15 & 3 & \\
3. Total firm exits & 43 & & & & & \\
$\begin{array}{l}\text { 4. Market size } \\
\text { a }\end{array}$ & $1857: 530-1610$ & $1857: 390-1270$ & $1857: 310-950$ & $1857: 70-210$ & $1857: 240-720$ & $1857: 1400-4200$ \\
& $1913: 2300$ & $1913: 2000$ & $1913: 900$ & $1913: 300$ & $1913: 2600$ & $1913: 8100$ \\
5. Share of global & $1862: 50.0 \%$ & $1862: 3.0 \%$, & $1862: 40.0 \%$ & $1862: 2.5 \%$ & $1862: 0.0 \%$ & $1862: 4.5 \%$ \\
market $^{\mathrm{a}}$ & $1873: 18.0 \%$ & $1873: 50.0 \%$ & $1873: 17.0 \%$ & $1873: 13.0 \%$ & $1873: 0.2 \%$ & $1873: 1.8 \%$ \\
& $1913: 6.5 \%$ & $1913: 74.1 \%$ & $1913: 5.4 \%$ & $1913: 7.0 \%$ & $1913: 3.3 \%$ & $1913: 3.7 \%$ \\
\hline
\end{tabular}

Notes for Table 8

The data comes from Homburg and Murmann (2014) except for market size and share data, whose sources are provided in notes $\mathrm{a}$ and $\mathrm{b}$

a Exact figures for market demand in 1857 are not available. However, it is possible to specify lower and upper bounds. The number of consumers is assumed to increase linearly in each region. The number of consumers at the beginning of the simulation (1856) is estimated to be 59,000. This number is derived from the following considerations: In the UK 75,000 $\mathrm{t}$ of natural dyes were consumed in 1856. This amounts to around $14 \%$ of the world consumption. Hence, around $535,000 \mathrm{t}$ of natural dyes were consumed worldwide. The literature reports that $1 \mathrm{t}$ of synthetic dye replaced around $9 \mathrm{t}$ of natural dye. Therefore, the consumption in 1856 would equal around $59,000 \mathrm{t}$ of synthetic dyes. To distribute these consumers across the different countries two assumptions are made: First, there is a worldwide increase in the demand for dyes. Second, in each country the demand for dyes increases linearly with the growth of the population. Both increases are assumed to be linear, so that only data for the population in each country in 1856 and 1913 has to be used to calculate the number of consumers in each region in 1856. This leads to the following numbers for 1856: 10,700 in UK, 7800 in G, 6300 in F, 1.400 in SW, 4.800 in USA and 28.000 in the rest of the world. Since these numbers represent rough estimates of the real demand in 1856, we defined a range of values that could have represented the true historical demand. We determined the historical demand to range between 0.5 and 1.5 times the estimated demand and divided by a factor by 10 to make them more convenient for representation

Precise estimates are available for 1913 based on the following information: In the year 1913 almost only synthetic dyes were consumed. We use the number of tons of synthetic dyes consumed in each country as a proxy for the demand at this time. This data is provided in Reader (1970, p. 258)

b The 1862 figures are from Leprieur and Papon (1979, p. 207). The authors report that Germany and Switzerland together held $5 \%$ of the market. We estimate that Germany's share amounted to 3 $\%$ and the Swiss share to $2 \%$. The 1873 figures were put together by Ernst Homburg from Hofmann 1873, p. 108; Wurtz 1876, p. 235 and Kopp 1874, p. 153). The 1912 figures are from Thissen (1922). Except in the case of Germany, we did not have figures for the year 1893 . We estimated the countries' market shares by assuming that market shares declined between 1873 and 1914 in a linear fashion 


\section{Appendix 2: some additional description of the simulation model and approach}

\section{A 2.1 Firm strategy}

In the model by Brenner and Duschl (2014) each firm is characterized by a strategy variable that ranges from 0 to 1 and determines whether a firm is more an imitator $(0)$ or an innovator (1). In the original model (Brenner and Duschl 2014) this variable is randomly drawn when a firm is founded and remains constant during its existence. From historical records we know that in the dye industry many firms started as imitators and developed into innovators. Therefore, the strategy value is set to 0.01 for each firm at its foundation. Then, after each year it is tested whether the sales of a firm decreased by more than $\Phi_{\text {strat,react }} \%$. If this is the case, the strategy variable is increased by $\Phi_{\text {strat,increase }}$ as long as the value of 1 is not reached. The reaction level $\Phi_{\text {strat,react }}$ is randomly drawn for each firm at its foundation between 0 and 1 . The strategy increase $\Phi_{\text {strat,increase }}$ is randomly drawn for each simulation between 0.05 and 0.25 .

\section{A 2.2 Innovation processes and start-ups}

The original model by Brenner and Duschl (2014) considers innovation as the appearance of new market packages that firms compete for, whereby those firms that follow an innovative strategy have a higher probability to win the new markets. We change two aspects of their original modeling: In our model market packages are characterized by two technological variables, namely technological advancement $a_{m}$ and type $y_{m}$ (see Section A 2.3) and firms are more active and determine the appearance of new market packages.

For the detection of a new market an basic innovation rate $\Phi_{\text {inпо, } 0}$ is defined. The probability of a firm to innovate (detect a new market) is given by this rate multiplied by the firms total market share and the free capacity of the firm as well as the R\&D activities of the firm (as in Brenner and Duschl 2014). The R\&D activities of a firm are defined to depend on the number of chemists employed (see above). If a firm is able to innovate, a new market package appears. The technology type $y_{m}$ and technological advancement $a_{m}$ are randomly drawn from an area that deviates maximally by 1 from the technological advancement and maximally by $\Phi_{\text {type,inno }}$ from the technology type of the existing products of the firm. A country is randomly assigned to the market package. Before the market package is finally created in the simulation it is checked whether an existing patent forbids the firm to produce this product. Only if this is not the case the market package is created and the innovative firm is the new owner.

We still assume that new firms might enter the industry with innovations (new market packages). To this end, the procedure above is repeated with a potential new firm innovating on the basis of an existing product (market package). The likelihood of such an event is given by

$$
\phi_{\text {inno }, 0} \cdot \phi_{\text {inni,start-up }} \cdot c_{\text {reg, unempl }}^{\phi_{\text {star- }, \text { chem }}},
$$

where $\Phi_{\text {inno,start-up }}$ is a parameter reflecting the probability of new firms entering with innovations in contrast to the innovation probability of incumbents, $\Phi_{\text {start-up, chem }}$ is a parameter defining the dependence of the start-up probability on the number of 
unemployed chemists in a country reg ("reg" standing for the countries UK, G, F, S and USA) (drawn randomly from a range between 0 and 1 for each simulation group), and $c_{\text {reg,unempl }}$ represents the number of unemployed chemists. This means that we make the number of start-ups dependent on the number of chemists that might found a firm. To determine the technological characteristics of the new market package, one existing market package is drawn randomly and the procedure described above is repeated including the check for patents. If the resulting technology is not covered by an existing patent, a new market package and firm is generated in the simulation model.

\section{A 2.3 Market space}

Dyes differ with respect to many characteristics. The most obvious is their color. Further aspects are the underlying chemical technology, textiles for which it can be used or durability. In our simulation model we simplify the situation by using only one value, $y_{m}$, which ranges between 0 and 1 to reflect these characteristics. Each market package has a unique value (see above) reflecting the demand for one specific combination of characteristics.

Innovations lead to new values of $y_{m}$ (see above). However, innovations usually do not change all characteristics at once. Hence, to estimate the technological distance, $\Phi_{\text {type,inno, that can be bridged by an innovation, we }}$ use the following considerations. Historically there are around 5 product classes that differ in their underlying chemical technology (aniline, alizarin, azo dyes, sulfur dyes, and synthetic indigo). Furthermore, seven classes of color (red, orange, yellow, green, blue, violet, black) exist, which leads to 35 classes. Most innovations will appear within these classes. However, within these classes the synthetic dyes still differ in their durability, the textiles for which they can be used, and similar characteristics. In order to restrict our parameter not too much, we assume between 40 and 1000 different technologies leading to $0.001<\Phi_{\text {type, inno }}<0.025$.

\section{A 2.4 Market size}

The initial (1857) potential market sizes can be estimated as between 530 and 1610 for UK, between 390 and 1270 for Germany, between 310 and 950 for France, between 70 and 210 for Switzerland, between 240 and 720 for the US and between 1400 and 4200 for the rest of the world. We draw random sizes from these ranges for each simulation run. The values reflect the whole demand for dyes. Of course, at the beginning most of this demand is not satisfied by synthetic dye producers (see above). If firms innovate (see above) and an existing market packages that is currently not owned by a synthetic dye firm (but by a natural dye firm, not explicitly modeled here) is technologically reachable, they will not generate a new market package but occupy such an existing market package. Such an innovation is by a factor $\Phi_{\text {exist,inno }}$ more likely than an innovation leading to a new market package. The total potential market size is assume to increase linearly over time to reach 2300 in UK, 2000 in Germany, 900 in France, 300 in Switzerland, 2600 in US and 8100 in the rest of the world by 1913. Since new market packages appear randomly due to innovation processes by the firms, we have to control the development of the market size. If the market size in the simulation model exceeds the presupposed market size development in a country, market packages are 
deleted until the values fit again. To this end, for each existing market package in a country the following value is calculated:

$$
a_{m}+\phi_{\text {dens }} \cdot \sum_{n \neq m}\left|y_{n}-y_{m}\right|
$$

Each time the market package with the lowest value disappears. The first term implies that market packages with a lower technological advancement are more likely to disappear. The second term implies that market packages with more technologically similar other market packages are more likely to disappear. $\Phi_{\text {dens }}$ determines the relative importance of these two aspects. In contrast to the model by Brenner and Duschl (2014), market packages do not disappear randomly in our model but their disappearance is modeled such that the total market size follows the historically known path. This implies that a higher innovative activity (creating more new market packages) of firms increases the probability of the disappearance (in this sence replacement) of existing market packages.

\section{A 2.5 Chemists}

Historical records show that the number of chemists per tons of synthetic dyes sales ranges between 0.0006 and 0.01 (these are the minimum and maximum share of chemists that were employed by the firms Bayer, BASF, Jäger and Levinstein at the end of the period of time studied. For a detailed study of these firms, see Murmann 2003). Therefore, for each firm a random chemist rate $\Phi_{\text {chem, rate }}$ is drawn from this range when the firm is founded. In addition, the number of chemists also depends on a firm's innovation strategy $s_{f}$, because innovation processes require chemical expertise. Thus, the desired number of chemists of a firm $f$ is given by

$$
c_{f}(t)=1+T_{f} \cdot \phi_{\text {chem }, \text { rate }} \cdot S_{f},
$$

where $T_{f}$ denotes the firm's sales.

If a firm cannot employ the desired number of chemists it employs as many chemists as it can get. The real strategy $s_{f \text {,real }}$ of a firm depends on the number of chemists that it is able to employ. If this number is lower than the one that matches the intended

\begin{tabular}{|c|c|c|c|c|c|}
\hline \multirow[t]{2}{*}{ Origin } & \multicolumn{5}{|c|}{ Destination } \\
\hline & UK & $\mathrm{G}$ & $\mathrm{F}$ & SW & USA \\
\hline UK & - & 0.005 & 0.005 & 0 & 0.02 \\
\hline G & 0.025 & - & 0.01 & 0.045 & 0.005 \\
\hline $\mathrm{F}$ & 0.01 & 0.005 & - & 0.05 & 0 \\
\hline SW & 0.003 & 0.1 & 0.006 & - & 0.001 \\
\hline USA & 0 & 0 & 0 & 0 & - \\
\hline
\end{tabular}

Table 9 Migration probabilities for chemists 
Table 10 Estimates of chemists and estimates for 1857 assuming exponentially increasing numbers

\begin{tabular}{llllll}
\hline Year & F & G & UK & SW & USA \\
\hline 1850 & 25 & 35 & 15 & 8 & 5 \\
1900 & 225 & 750 & 150 & 75 & 75 \\
estimate for 1857 & 34.0 & 53.8 & 20.7 & 10.9 & 7.3 \\
\hline
\end{tabular}

Source: Ernst Homburg (E-mail, November, 2002)

strategy, the strategy has to be adapted downwards and the firm acts less innovative than intended.

We assume that chemists prefer employment in a domestic dye company. Hence, if firms require additional chemists, they first employ unemployed chemists from the own country. If no unemployed chemists are available in the own country, firms search for chemists in other countries. Only a certain share of all chemists are willing to move to foreign countries. This share is fixed according to historical records as given in Table 9.

If the need of chemists decreases in a firm, chemists are fired and become unemployed.

\section{A 2.6 Simulation approach}

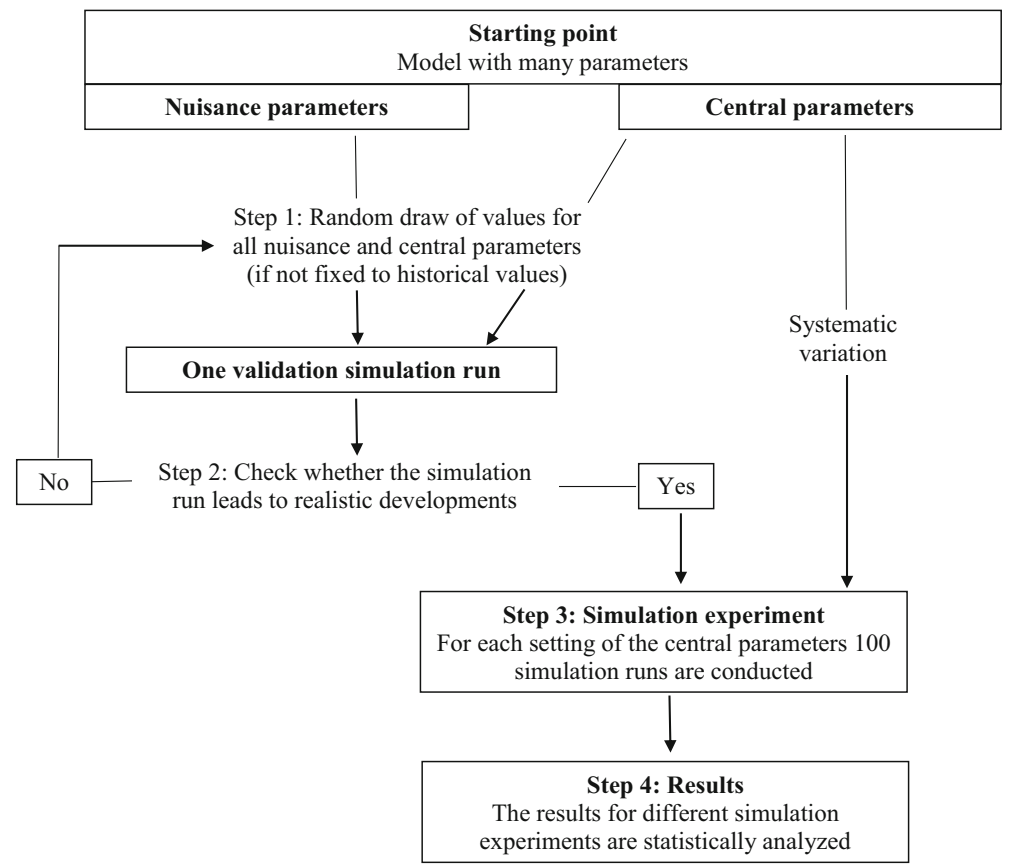

Fig. 1 Schematic graph of the successive steps in the simulation experiment method 


\section{References}

Allen RC (2003) Progress and poverty in early modern Europe. Econ Hist Rev 56(3):403-443. doi:10.1111/j. 1468-0289.2003.00257.x

Arthur WB (1994) Increasing returns and path dependence in the economy. University of Michigan Press, Ann Arbor

Beer JH (1959) The emergence of the German dye industry. University of Illinois Press, Urbana

Brenner T, Duschl M (2014) Modelling firm and market dynamics: a flexible model reproducing existing stylized facts. Working Papers on Innovation and Space, vol 07.14. Philipps-Universität Marburg

Brenner T, Werker C (2007) A taxonomy of inference in simulation models. Comput Econ 30(3): $227-244$

Buenstorf G, Klepper S (2009) Heritage and agglomeration: the akron tyre cluster revisited. Econ J 119(537): 705-733

Caro H (1892) Über die Entwicklung der Theerfarben-Industrie (About the develpment of the coal-tar industry). Ber Dtsch Chem Ges 25(3):955-1105

David PA (1985) Clio and the economics of QWERTY. Am Econ Rev 75(2):332-337

De Vaan M, Boschma R, Frenken K (2013) Clustering and firm performance in project-based industries: the case of the global video game industry, 1972-2007. J Econ Geogr 13(6):965-991

Freeman C (1982) The economics of industrial innovation, 2nd edn. The MIT Press, Cambridge

Heimeriks G, Boschma R (2014) The path-and place-dependent nature of scientific knowledge production in biotech 1986-2008. J Econ Geogr 14(2):339-364

Hofmann AW (1873) Einleitung. In: Amtlicher Katalog der Ausstellung des Deutschen Reiches. Wiener Weltausstellung. Gruppe III: Chemische Industrie (Official Catalog of Exhibit by the German Empire. Vienna World Exhibition. Group III. Chemical Industry). Berlin, pp 95139

Homburg E, Murmann JP (2014) Global database of synthetic dye firms and plants, 1857-1914. http:// professor-murmann.net/dye-database.html. Accessed 28 Oct 2014.

Klepper S (2007) Disagreements, spinoffs, and the evolution of Detroit as the capital of the US automobile industry. Manag Sci 53(4):616-631. doi:10.1287/mnsc.1060.0683

Kopp E (1874) Wiener Weltaustellung 1873 (Vienna World Exhibition 1873). In: Bericht über Gruppe III, Chemische Industrie (Report on Group III, Chemical Industrie), vol 8. C. Baader, Schaffhausen

Krugman P (1995) Development, Geography, and Economic theory. MIT Press, Cambridge

Landes DS (1969) The unbound prometheus: technological change and industrial development in Western Europe from 1750 to the present. Cambridge University Press, New York

Leprieur F, Papon P (1979) Synthetic dyestuffs: the relations between academic chemistry and the chemical industry in nineteenth-century France. Minerva 17(2):197-224

Malerba F, Nelson R, Orsenigo L, Winter S (1999) 'History-friendly' models of industry evolution: the computer industry. Ind Corp Chang 8(1):3-40

Malerba F, Nelson R, Orsenigo L, Winter S (2008) Vertical integration and disintegration of computer firms: a history-friendly model of the coevolution of the computer and semiconductor industries. Ind Corp Chang 17(2):197-231

Murmann JP (2003) Knowledge and competitive advantage: the coevolution of firms, technology, and national institutions. Cambridge University Press, New York

Murmann JP (2013) The coevolution of industries and important features of their environments. Organ Sci 24(1):58-78. doi:10.1287/orsc.1110.0718

Murmann JP, Homburg E (2001) Comparing evolutionary dynamics across different national settings: the case of the synthetic dye industry, 1857-1914. J Evol Econ 11(2):177-205

Reader WJ (1970) Imperial chemical industries: a history. Vol. I. Oxford University Press, London

Redlich F (1914) Die volkwirtschaftliche bedeutung der deutschen teerfarbenindustrie. Staats-und sozialwissenschaftliche forschungen 180. Duncker \& Humblot, München-Leipzig

Sydow J, Schreyögg G, Koch J (2009) Organizational path dependence: opening the black box. Acad Manag Rev 34(4):689-709

Teltschik W (1992) Geschichte der Deutschen grosschemie: entwicklung und einfluss in staat und gesellschaft (History of the large-scale German chemical industry: development and impact on state and society). $\mathrm{VCH}$, Weinheim 
Thissen F (1922) Die Stellung der deutschen Teerfarbenindustrie in der Weltwirtschaft (vor, in, und nach dem Kriege) [The Position of the German Tar Color Industry in the Global Economy before, during, and after the War]. Doctoral Dissertation. University of Giessen

Wenting R, Frenken K (2011) Firm entry and institutional lock-in: an organizational ecology analysis of the global fashion design industry. Ind Corp Chang 20(4):1031-1048

Wurtz A (1876) Progrès de L'industrie des Matières Colorantes Artificielles (The progress of the synthetic dye industry). G. Masson, Paris 